\title{
Endovascular Treatment in the Subclavian Steal Syndrome
}

\section{Tratamento endovascular na síndrome do roubo da subclávia}

\author{
Luana Antunes Maranha Gatto ${ }^{1}$ Jennyfer Paulla Galdino Chaves ${ }^{1}$ Cássio Henrique Mendes ${ }^{1}$ \\ Diego do Monte Rodrigues Seabra ${ }^{1}$ Gelson Luis Koppe ${ }^{1}$ Zeferino Demartini Junior ${ }^{1}$
}

\footnotetext{
${ }^{1}$ Department of Neurosurgery and Interventional Neuroradiology, Hospital Universitário Cajuru, Curitiba, Paraná, Brazil

Arq Bras Neurocir 2019;38:137-140.
}

\begin{abstract}
Address for correspondence Luana Antunes Maranha Gatto, MD, Departamento de Neurocirgurgia e Neurorradiologia Intervencionista, Hospital Universitário Cajuru, Rua São Jose, 300, Curitiba, PR, 80050-350, Brazil (e-mail: luanamaranha@yahoo.com.br).
\end{abstract}

\author{
Abstract \\ Keywords \\ - subclavian steal \\ syndrome \\ - subclavian artery \\ stenosis \\ - subclavian steal \\ phenomenon \\ - cerebrovascular \\ circulation \\ - atherosclerosis \\ - syncope

\section{RESUMO \\ Palavras-chave \\ - síndrome do roubo da subclávia \\ - estenose da artéria subclávia \\ - fenômeno do roubo da subclávia \\ - circulação cerebrovascular \\ - aterosclerose \\ - síncope}

When the proximal occlusion or stenosis of the subclavian or of the brachiocephalic artery may require distal arterial filling through reversal flow from the vertebral artery, causing clinically significant blood supply reduction to the brainstem, it is called subclavian steal syndrome (SSS). We report a 54-year-old male patient who presented with multiple episodes of syncopes and vascular claudication due to right SSS. He underwent an angioplasty, evolving with complete improvement of the symptoms. We review the clinical presentation, the diagnostic methods, and the treatment options of the disease.
A oclusão ou estenose da artéria subclávia ou do tronco braquiocefálico pode exigir fluxo reverso pela artéria vertebral para seu enchimento distal, causando sintomas devido à redução de fluxo no tronco encefálico. $\mathrm{A}$ isso se dá o nome de síndrome do roubo da subclávia. Relatamos o caso de um paciente de 54 anos com múltiplos episódios de síncope e claudicação vascular por síndrome do roubo da subclávia à direita, submetido a angioplastia e evoluindo com melhora completa dos sintomas. Revisamos a apresentação clínica, métodos diagnósticos e opções de tratamento da doença.

(1)Luana Antunes Maranha Gatto's ORCID is https://orcid.org/00000002-1940-2689.

received

November 11, 2018

accepted

February 19, 2019
DOI https://doi.org/

10.1055/s-0039-1685152. ISSN 0103-5355.
Copyright $\odot 2019$ by Thieme Revinter

Publicações Ltda, Rio de Janeiro, Brazil
License terms

(c) (1) $\ominus$ (\$) 


\section{Introduction}

Subclavian steal syndrome (SSS) is a vascular process resulting from an ipsilateral occlusion or from a significant proximal stenosis of the subclavian or braquiocephalic arteries. $^{1}$ With pressure impairment in the subclavian artery, blood flows from the contralateral vertebral artery to the basilar artery and descends retrogradely through the ipsilateral vertebral artery, leading to collateral circulation to the upper limb. ${ }^{1}$

Significant subclavian or braquiocephalic artery stenosis or occlusions, however, are mostly asymptomatic and, therefore, do not require specific therapy other than those directed to the underlying etiology. ${ }^{2,3}$ However, when symptoms do occur, the most common manifestations are symptoms of vertebrobasilar insufficiency, such as dizziness and diplopia, or symptoms of upper limb ischemia, such as weakness, paresthesia, numbness, and coldness. These symptoms are often associated with arm exercises. ${ }^{4-7}$

Rarely, however, some patients may provoke exercise syndrome and present with transitory ipsilateral arm claudication, ataxia and/or angina. ${ }^{8}$ It is often a differential diagnosis in any patient who has a pulse deficit or a systolic blood pressure difference greater than $20 \mathrm{mmHg}$ between the arms. ${ }^{8}$

Atherosclerosis is the main cause of occlusive disease involving the subclavian artery, with concomitance of smoking in 78 to $100 \%$ of the cases, of coronary artery disease in 27 to $65 \%$ of the cases, and of carotid or vertebral arterial disease in one third of the patients. ${ }^{9-11}$

\section{Case Report}

A 59-year-old male presented with multiple episodes of syncope and lower limb vascular claudication during his work (cabinet maker) for $\sim 2$ years. He had a history of hypertension and smoking and was submitted to bilateral femoral popliteal bypass surgery 1 year before, with total improvement of the claudication of the lower limbs. He had also undergone a bilateral carotid artery angioplasty 6 months earlier due to severe stenosis, but the syncopes remained. The cardiologic investigation and the neurological examination were normal, but blood pressure was $40 \mathrm{mmHg}$ different between his arms. A cervical and intracranial digital subtraction angiography (DSA) showed a severe stenosis of the right subclavian artery, with reverse blood flow in the ipsilateral vertebral artery irrigating the right upper limb, characterizing the SSS ( - Fig. 1). Thus, the patient underwent a right subclavian artery angioplasty with stent and balloon (-Fig. 2 ). The procedure was performed through a right femoral access, under general anesthesia and full intravenous heparinization. A Destination peripheral guiding sheath (Terumo, Tokyo, Japan) was positioned in the brachiocephalic trunk and a Protégé RX stent (Medtronic, Dublin, Ireland) with $10 \times 7 \mathrm{~mm}$ of diameter and $40 \mathrm{~mm}$ of extension was delivered crossing the stenosis. Although the stent produced partial vessel opening, an Armada balloon catheter (Abbott, Chicago, IL, USA) of $9 \times 40 \mathrm{~mm}$ inflated until 13 Atm achieved definitive stent impingement and normalization of the cervical and of the intracranial blood flow. In the postoperative period, he maintained the use of simvastatin $40 \mathrm{mg}$, enalapril $20 \mathrm{mg}$, and

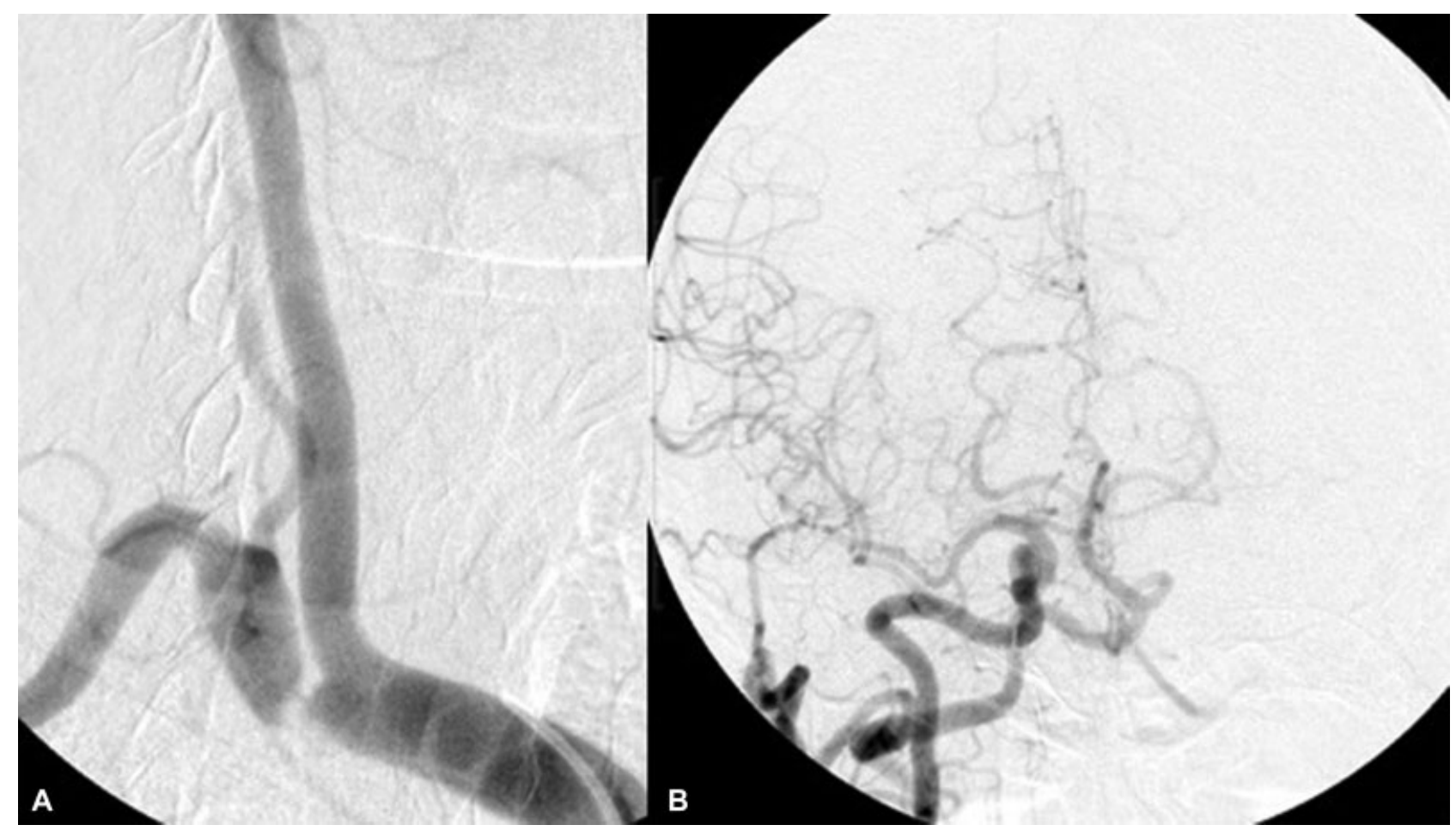

Fig. 1 A: Right subclavian artery with suboclusive stenosis and a retrograde flow in the vertebral artery. Right anterior oblique view. B: Right common carotid artery and filling of the posterior circulation through extraintracranial anastomosis. Anteroposterior view. 


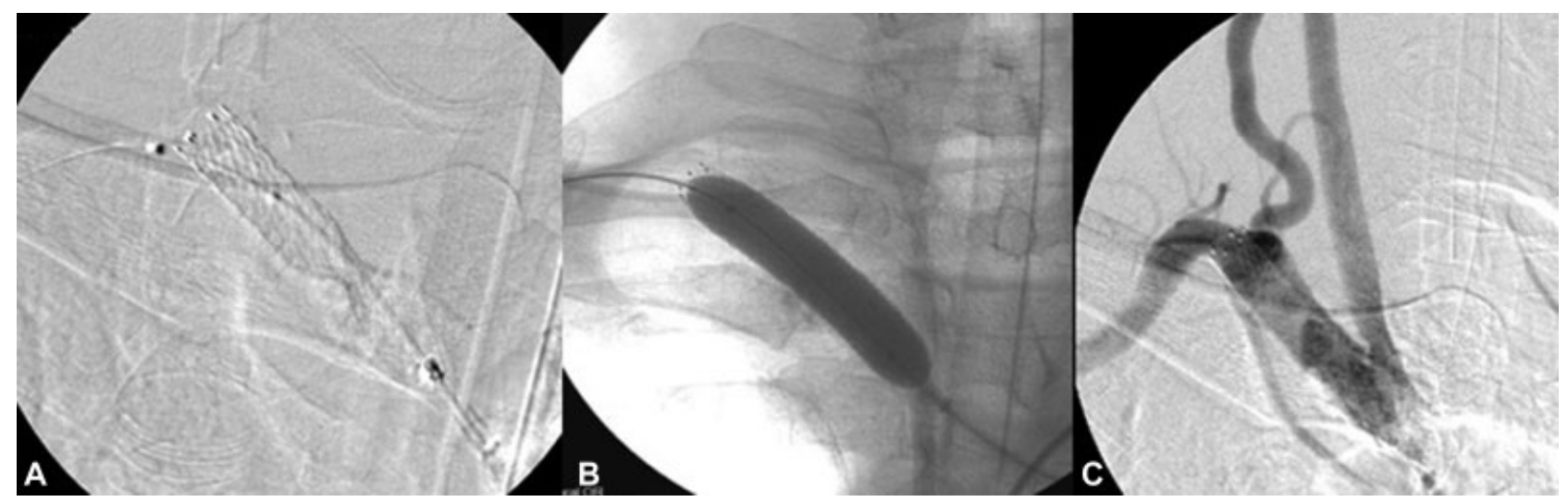

Fig. 2 Angioplasty. A: Delivered and opened stent covering the entire stenosis. B: Inflating the balloon. C: Satisfactory final result.

double antiaggregation (aspirin $100 \mathrm{mg}$ and clopidogrel $75 \mathrm{mg}$ ) daily. There were no further syncopes or claudication of the arm during 16 months of follow-up, without difference of blood pressure between the arms, despite the patient having not stopped smoking.

\section{Discussion}

\section{Clinical Presentation}

Subclavian steal syndrome is a rare disease, related in $\sim 6 \%$ of asymptomatic patients with cervical murmurs. ${ }^{5}$

In the majority of the patients, a subclavian severe stenosis with or without flow reversal in the ipsilateral vertebral artery is clinically asymptomatic., ${ }^{5,12}$ It occurs due to the slow progression of the disease and to the development of collateral circulation. ${ }^{13,14}$

However, patients with flow reversal can become symptomatic if the collateral blood supply from the vertebrobasilar circulation cannot accommodate the increased demand, such as during exercise or in the setting of an arteriovenous fistula. ${ }^{15}$

The symptoms of subclavian disease include ipsilateral claudication of the superior extremity (that can be correlated with Takayasu arteritis) and vertebrobasilar insufficiency, such as the syncopes of our patient, or even posterior fossa stroke and myocardial ischemia. ${ }^{3,5,9,15}$ Among the clinical manifestations, vertigo or dizziness are the most prevalent. ${ }^{7}$ Other possible symptoms include ataxia, tinnitus, drop attacks, visual disturbances, perioral numbness, alternating paresthesia, dysphagia, dysarthria, transient amnesia, or headache. ${ }^{3,5,9,15}$

Complete occlusion is three times more prevalent in the left subclavian artery than in the right subclavian or in the innominate artery. ${ }^{16}$

\section{Diagnosis}

In the physical examination, a discrepancy of $>15$ to $20 \mathrm{mmHg}$ in the arm blood pressure (ABP) taken in both upper extremities can be found, beyond pulse impairment in the affected side. ${ }^{4,12}$ In a study by Osborn et al, ${ }^{14}$ a systolic ABP difference $\geq 15 \mathrm{mmHg}$ had a positive and negative predictive value of $100 \%$ for SSS, in a total of 59 patients. On the other hand, English et al found in the difference in systolic $\mathrm{ABP} \geq 20 \mathrm{mmHg}$ the positive and negative predictive values of 19 and $98 \%$, respectively. ${ }^{17,18}$

Recent studies have shown a linear correlation between the increase of the ABP difference with the occurrence of symptoms. ${ }^{19,20}$ Labropoulos et al reported that $38.5 \%$ in the group with ABP difference $50 \mathrm{mmHg}$ presented symptoms. ${ }^{19}$

The arterial insufficiency syndrome can lead to skin modification, but only $5 \%$ of the patients have cyanosis and trophic skin changes due to severe brachial ischemia or embolism in the distal arterial branches of the upper limbs. ${ }^{12,21}$ Also, an audible bruit over the supraclavicular fossa can be heard. ${ }^{4,12}$

The diagnosis can be done with the use of a Doppler ultrasound guided by an experienced professional, with findings such as waveform dampening or monophasic changes. ${ }^{22}$ When the Doppler is inconclusive, it is possible to use a more invasive diagnosis test, such as angioresonance or angiotomography, both showing the grade of the stenosis. ${ }^{12}$ However, DSA still is the gold standard test due to the dynamic visualization of the retrograde vertebral flow. ${ }^{22}$

\section{Treatment}

A small percentage of patients with SSS really need any therapeutic intervention. ${ }^{4,19,22}$ The surgical options, such as bypass grafting, or endovascular treatments involving angioplasty and stenting, are often reserved for serious clinical symptoms. ${ }^{4}$

Asymptomatic patients should not be submitted to interventions, ${ }^{4,7}$ since they could prevent future disease with medical therapy, which includes antiplatelet drugs, such as aspirin, and a lipid-lowering statin therapy with a goal of lowdensity protein (LDL) cholesterol $<100 \mathrm{mg} / \mathrm{dL}^{4,7,22}$ Stopping smoking, controlling the blood pressure, and glycated hemoglobin $\mathrm{A} 1 \mathrm{C}$ rate $<7 \%$ are advised ${ }^{7}$ to reduce the morbidity and mortality risk related to atherosclerotic disease, which can lead to ischemic events in the heart and in the brain. ${ }^{4}$ Subclavian stenosis is an atherosclerotic disease marker and, as a consequence, cardiological (heart attack) and brain (stroke) events should be warned of the possibility of occurence. ${ }^{18,22}$

The surgical vascular intervention options include: axillaryaxillary bypass, carotid-subclavian bypass, and transposition of the subclavian artery. ${ }^{22}$ The carotid-subclavian bypass 
showed low risk of mortality and small recurrence rates. ${ }^{4}$ Law et $\mathrm{al}^{21}$ found in their study that transpositions have the highest long-term 5-year patency rate (100\%), followed by PTFE (95\%) and Dacron grafts (84\%), and saphenous vein grafts have the lowest patency rate $(65 \%){ }^{23}$

Percutaneous transluminal angioplasty (PTA) has a high rate of patency for subclavian stenosis or occlusion, the latter with a lower rate. Percutaneous transluminal angioplasty has a high rate of good outcome and a low incidence of recurrence, especially in proximal stenosis. ${ }^{16-18}$ It is done with local puncture and, therefore, has lower rates of complications; stenting has been considered safe when you compare it with the surgical vascular intervention. ${ }^{18}$ In a series of 110 patients treated by PTA with a follow-up of almost 3 years, patients with subclavian stenosis and occlusion had patency rates of 93 and $65 \%$, respectively. ${ }^{16}$

Risks related to PTA are stroke, arterial rupture, stent migration, and reocclusion. ${ }^{18}$ Patients who already had an occlusion presented with a high rate of reocclusion (35$50 \%){ }^{17,18} \mathrm{~A}$ regular follow-up for at least 2 years postPTA is recommended. ${ }^{18}$

None of the studies reviewed in the present article clarifies how long a patient with total occlusion is still submitted to an intervention with angioplasty.

Prospective randomized studies are needed to elucidate the fact that several papers analyze subclavian PTA in stenosis and occlusion, but they do not mention whether or not they have clinical and/or angiographic criteria for SSS.

\section{Conclusions}

Subclavian steal syndrome is a rare vascular condition related to cerebrovascular risk factors, with a wide clinical presentation, but normally asymptomatic. Endovascular treatment with stent and balloon, as performed in the related patient, is safe and has good long-term results. Intervention is only indicated in symptomatic patients.

Conflicts of Interests

The authors have no conflicts of interests to declare.

\section{References}

1 Fisher CM. A new vascular syndrome - "the subclavian steal. N Engl J Med 1961;265:912-913

2 Reivich M, Holling HE, Roberts B, Toole JF. Reversal of blood flow through the vertebral artery and its effect on cerebral circulation. N Engl J Med 1961;265:878-885

3 Hennerici M, Klemm C, Rautenberg W. The subclavian steal phenomenon: a common vascular disorder with rare neurologic deficits. Neurology 1988;38(05):669-673

4 Osiro S, Zurada A, Gielecki J, Shoja MM, Tubbs RS, Loukas M. A review of subclavian steal syndrome with clinical correlation. Med Sci Monit 2012;18(05):RA57-RA63
5 Fields WS, Lemak NA. Joint Study of extracranial arterial occlusion. VII. Subclavian steal-a review of 168 cases. JAMA 1972;222 (09):1139-1143

6 Taylor CL, Selman WR, Ratcheson RA. Steal affecting the central nervous system. Neurosurgery 2002;50(04):679-688, discussion 688-689

7 Psillas G, Kekes G, Constantinidis J, Triaridis S, Vital V. Subclavian steal syndrome: neurotological manifestations. Acta Otorhinolaryngol Ital 2007;27(01):33-37

8 Takach TJ, Reul GJ, Cooley DA, et al. Myocardial thievery: the coronary-subclavian steal syndrome. Ann Thorac Surg 2006;81 (01):386-392

9 Pollard H, Rigby S, Moritz G, Lau C. Subclavian steal syndrome: a review. Australas Chiropr Osteopathy 1998;7(01):20-28

10 Lacey KO. Subclavian steal syndrome: a review. J Vasc Nurs 1996; 14(01):1-7

11 Brountzos EN, Petersen B, Binkert C, Panagiotou I, Kaufman JA. Primary stenting of subclavian and innominate artery occlusive disease: a single center's experience. Cardiovasc Intervent Radiol 2004;27(06):616-623

12 Potter BJ, Pinto DS. Subclavian steal syndrome. Circulation 2014; 129(22):2320-2323

13 Shadman R, Criqui MH, Bundens WP, et al. Subclavian artery stenosis: prevalence, risk factors, and association with cardiovascular diseases. J Am Coll Cardiol 2004;44(03):618-623

14 Osborn LA, Vernon SM, Reynolds B, Timm TC, Allen K. Screening for subclavian artery stenosis in patients who are candidates for coronary bypass surgery. Catheter Cardiovasc Interv 2002;56 (02):162-165

15 Contorni L. [The vertebro-vertebral collateral circulation in obliteration of the subclavian artery at its origin]. Minerva Chir 1960; $15: 268-271$

16 De Vries JP, Jager LC, Van den Berg JC, et al. Durability of percutaneous transluminal angioplasty for obstructive lesions of proximal subclavian artery: long-term results. J Vasc Surg 2005;41(01):19-23

17 English JA, Carell ES, Guidera SA, Tripp HF. Angiographic prevalence and clinical predictors of left subclavian stenosis in patients undergoing diagnostic cardiac catheterization. Catheter Cardiovasc Interv 2001;54(01):8-11

18 Fregni F, Castelo-Branco LE, Conforto AB, et al. Treatment of subclavian steal syndrome with percutaneous transluminal angioplasty and stenting: case report. Arq Neuropsiquiatr 2003; 61(01):95-99

19 Labropoulos N, Nandivada P, Bekelis K. Prevalence and impact of the subclavian steal syndrome. Ann Surg 2010;252(01): $166-170$

20 Rodriguez-Lopez JA, Werner A, Martinez R, Torruella LJ, Ray LI, Diethrich EB. Stenting for atherosclerotic occlusive disease of the subclavian artery. Ann Vasc Surg 1999;13(03):254-260

21 Law MM, Colburn MD, Moore WS, Quiñones-Baldrich WJ, Machleder HI, Gelabert HA. Carotid-subclavian bypass for brachiocephalic occlusive disease. Choice of conduit and long-term follow-up. Stroke 1995;26(09):1565-1571

22 Ochoa VM, Yeghiazarians Y. Subclavian artery stenosis: a review for the vascular medicine practitioner. Vasc Med 2011;16(01): 29-34

23 Hass WK, Fields WS, North RR, Kircheff II, Chase NE, Bauer RB. Joint study of extracranial arterial occlusion. II. Arteriography, techniques, sites, and complications. JAMA 1968;203(11): 961-968 